\title{
Experimental and Numerical Simulations of Phase Transformations Occurring During Continuous Annealing of DP Steel Strips
}

\author{
Andrzej Wrożyna, Monika Pernach, Roman Kuziak, and Maciej Pietrzyk
}

\author{
(Submitted November 12, 2015; in revised form December 27, 2015; published online February 25, 2016)
}

\begin{abstract}
Due to their exceptional strength properties combined with good workability the Advanced High-Strength Steels (AHSS) are commonly used in automotive industry. Manufacturing of these steels is a complex process which requires precise control of technological parameters during thermo-mechanical treatment. Design of these processes can be significantly improved by the numerical models of phase transformations. Evaluation of predictive capabilities of models, as far as their applicability in simulation of thermal cycles thermal cycles for AHSS is considered, was the objective of the paper. Two models were considered. The former was upgrade of the JMAK equation while the latter was an upgrade of the Leblond model. The models can be applied to any AHSS though the examples quoted in the paper refer to the Dual Phase (DP) steel. Three series of experimental simulations were performed. The first included various thermal cycles going beyond limitations of the continuous annealing lines. The objective was to validate models behavior in more complex cooling conditions. The second set of tests included experimental simulations of the thermal cycle characteristic for the continuous annealing lines. Capability of the models to describe properly phase transformations in this process was evaluated. The third set included data from the industrial continuous annealing line. Validation and verification of models confirmed their good predictive capabilities. Since it does not require application of the additivity rule, the upgrade of the Leblond model was selected as the better one for simulation of industrial processes in AHSS production.
\end{abstract}

Keywords DP steel, experimental simulations, numerical simulations, phase transformations

\section{Introduction}

Advanced high-strength steels (AHSS) are complex, sophisticated materials, with carefully selected chemical compositions and multiphase microstructures resulting from precisely controlled heating and cooling processes. Various strengthening mechanisms are employed to achieve a range of strength, ductility, toughness, and fatigue properties. In consequence, AHSS offer extremely attractive combinations of these properties. The AHSS are uniquely designed to meet the challenges of today vehicles as far as safety regulations and emissions reduction at affordable costs are considered.

The AHSS family includes Dual Phase (DP), ComplexPhase (CP), Ferritic-Bainitic (FB), Martensitic (MART), Transformation-Induced Plasticity (TRIP), and Twinning-Induced Plasticity (TWIP) (Ref 1). The 1st and 2nd Generation AHSS are uniquely qualified to meet the functional performance demands of certain parts. Due to their high energy absorption DP and TRIP steels are excellent example of material used for crash zone parts of a car. High-strength steels such as MART and boron-based Press Hardened Steels (PHS) ensure improved

\footnotetext{
Andrzej Wrożyna and Roman Kuziak, Institute for Ferrous Metallurgy, ul. K. Miarki 12, Gliwice, Poland; and Monika Pernach and Maciej Pietrzyk, AGH University of Science and Technology, al. Mickiewicza 30, 30-059 Kraków, Poland. Contact e-mail: pernach@agh.edu.pl.
}

safety performance when used for structural elements of passenger compartments. Recently there has been increased research for the development of the "3rd Generation" of AHSS (Ref 2). These are steels with improved strength-ductility combinations compared to present grades, with potential for more efficient joining capabilities, at lower costs.

The DP steel, which was selected for the analysis in the present paper, is a composite of ductile ferrite and hard martensite phases occasionally containing some bainite and retained austenite. This combination results in an increase of strength, hardening coefficient, and elongation in the tensile test. Such features are crucial when car body parts responsible for passengers safety are produced of steel (Ref 1, 3). The morphology and volume fraction of martensite, as well as its chemical composition and hardness, are the factors which influence properties of the products (Ref 4). Required relation between volume fractions of ferrite and martensite is obtained by applying special cooling paths. The general idea is fast cooling of the steel to the temperature of maximum rate of ferritic transformation, maintaining the temperature for the time needed to obtain required volume fraction of ferrite followed by fast cooling which transforms the remaining austenite into hard constituents. Practical realization of this cycle can be done either during laminar cooling after hot rolling (Ref 5) or during continuous annealing after cold rolling (Ref 6, 7). Both processes require precise control of the thermal cycle to obtain required microstructure of products. Therefore, before new generations of DP steels can be adopted and the potential benefits be achieved, many fundamental scientific and technical research issues must still be addressed. Numerical modeling is used to support timely and expensive experimental in this research and to design of optimal thermal cycles. 
A variety of models dedicated to the prediction of phase transformation kinetics during manufacturing of strips with DP structures were published. Applied solutions vary from fundamental JMAK equation to advanced models, which account explicitly for the material microstructure. Among numerous publications in this field those based on 3-D microstructure evolution model should be mentioned. Bos et al. (Ref 8) have proposed the model which allows study in detail the effect of individual process parameters (recrystallization, phase transformations) on the final microstructure. The model has been applied to describe transformations on the run-out table of the hot strip mill and in the continuous annealing line (Ref 9). Phase field model was applied in (Ref 6) to modeling phase transformations during annealing of cold rolled DP steel strip. Cellular Automata (CA) is another approach, which is used to describe phase transformations in DP steels, see Authors' publication on heating (Ref 10) and cooling (Ref 11) during annealing cycle. The models, which account explicitly for the material microstructure, require long computing times. This problem becomes particularly important when multiscale modeling technique is needed and phase transformation model in the micro scale has to be combined with the finite element

Table 1 Chemical composition of the investigated steels, wt.\%

\begin{tabular}{lllllll}
\hline Steel & C & Mn & Si & Cr & P & S \\
\hline A & 0.09 & 1.42 & 0.1 & 0.35 & 0.011 & 0.01 \\
B & 0.15 & 1.5 & 0.4 & 0.2 & 0.01 & 0.01 \\
\hline
\end{tabular}

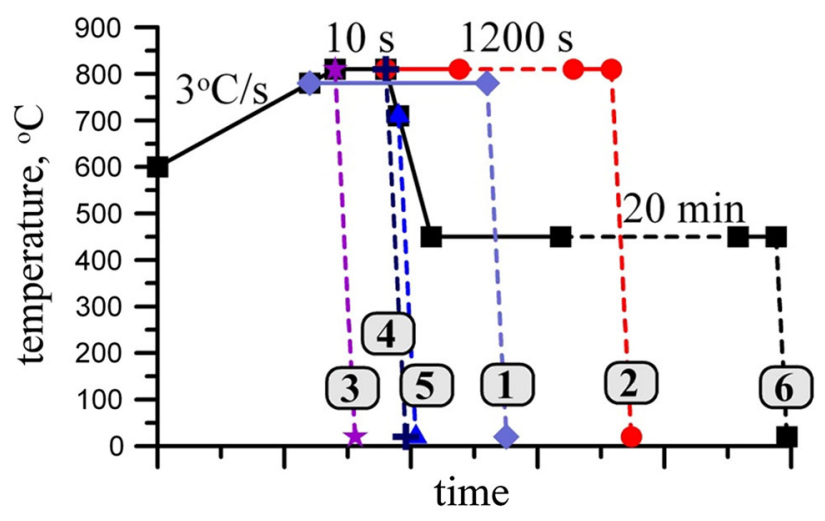

Fig. 1 Schematic illustration of the thermal cycles investigated in the laboratory tests using dilatometer DIL 805
(FE) method in the macro scale, see (Ref 12). Problem of searching for the balance between predictive capabilities of phase transformation models and the computing costs was discussed in Ref 13. In the present paper, experimental simulations of thermal cycles will be used to evaluate possibilities of the efficiency improvement of these models.

Conventional phase transformation model based on the Avrami equation was used by the Authors in publication (Ref 7) to simulate industrial process of the continuous annealing. Additivity rule which should be applied here to account for the temperature variations constitutes one of the most important drawbacks of this model. Therefore, an upgrade of the Leblond model (Ref 14), which is based on the differential equation with respect to time, was considered as an alternative. Many researchers successfully used the idea of description of kinetics transformation with differential equation, see applications to welding (Ref 15) and to DP steels (Ref 16). In the present paper, the approach based on the second order differential equation described in (Ref 17) was considered. The objective of the present paper was to evaluate the behavior of developed models in more complex thermal cycles and to investigate possibility of application of alternative models. Experimental simulations of the cycles, which go beyond the constraints of industrial lines, were performed on the dilatometer DIL 805. The results of experimental simulations were used to verify and validate the models.

\section{Experiments}

\subsection{Procedure}

Verification and validation of phase transformation models and their applicability to simulate industrial processes for advanced high-strength steels was the main objective of this paper. Experiments were performed to supply data for this verification and validation. The objective was reached in three steps. Experimental simulations of thermal cycles were performed for the steel with chemical composition given in Table 1 (steel A). The cycles were designed to enable verification and validation of models in the conditions going beyond the constraints of industrial annealing lines (Fig. 1; Table 2). The second set of tests included experimental simulation of the typical thermal cycle for the industrial continuous annealing line (Fig. 2). The steel manufactured in this line had the chemical composition given in the second row of Table 1 (steel B). The experimental simulations were performed on the dilatometer DIL 805 (Baehr-Thermoanalyse). The third step of the verification and validation of phase

Table 2 Parameters of the thermal cycles investigated in the laboratory tests using dilatometer DIL 805

\begin{tabular}{|c|c|c|c|c|c|}
\hline \multirow[b]{2}{*}{ Test } & \multicolumn{2}{|c|}{ Heating } & \multicolumn{2}{|c|}{ Cooling } & \multirow[b]{2}{*}{ Microstructure } \\
\hline & Temperature, ${ }^{\circ} \mathrm{C}$ & Time, $\mathbf{s}$ & Temperature, ${ }^{\circ} \mathrm{C}$ & Time, $s$ & \\
\hline 1 & 780 & 60 & 20 & Water & $\mathrm{F}+\mathrm{B}+\mathrm{M}$ \\
\hline 2 & 810 & 1200 & 20 & Water & $\mathrm{F}+\mathrm{B}+\mathrm{M}$ \\
\hline 3 & 810 & 0 & 20 & Water & $\mathrm{F}+\mathrm{B}+\mathrm{M}$ \\
\hline 4 & 810 & 10 & 20 & Water & $\mathrm{F}+\mathrm{B}+\mathrm{M}$ \\
\hline 5 & 810 & 10 & $710-20$ & Water & $\mathrm{F}+\mathrm{B}+\mathrm{M}$ \\
\hline 6 & 810 & 10 & 450 & 1200 & $F+B$ \\
\hline
\end{tabular}


transformation models included simulations of industrial continuous annealing process, which is described in Ref 18.

Experimental simulations were preceded by dilatometric tests, which were carried out to supply data for identification of the phase transformation models. The tests were performed on the dilatometer DIL 805. Dilatometric specimens with dimensions $0.9 \times 0.9 \times 7.0 \mathrm{~mm}$ were machined from cold rolled steel sheets with longitudinal direction parallel to rolling direction. The dilatometric specimens from steel A were heated to the annealing temperature of $920^{\circ} \mathrm{C}$ at heating rate $3{ }^{\circ} \mathrm{C} / \mathrm{s}$ and immediately cooled at series of linear rates from $1{ }^{\circ} \mathrm{C} / \mathrm{s}$ up to $332{ }^{\circ} \mathrm{C} / \mathrm{s}$. The dilatometric specimens from steel B were heated to the annealing temperature of $857^{\circ} \mathrm{C}$ according to the typical thermal cycle for the industrial continuous annealing line (Fig. 2) and cooled at series of linear rates from $30{ }^{\circ} \mathrm{C} / \mathrm{min}$ up to $335^{\circ} \mathrm{C} / \mathrm{s}$. After the tests all samples were subjected to the analysis of the microstructure using scanning microscope.

\subsection{Results}

After quenching all samples were subjected to the microstructure analysis with the use of scanning microscope.

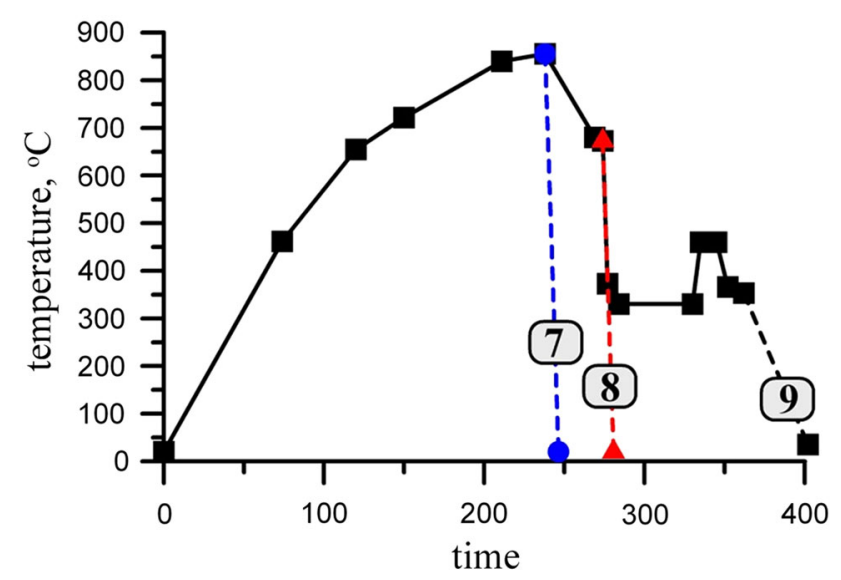

Fig. 2 Typical thermal cycle for the continuous annealing line

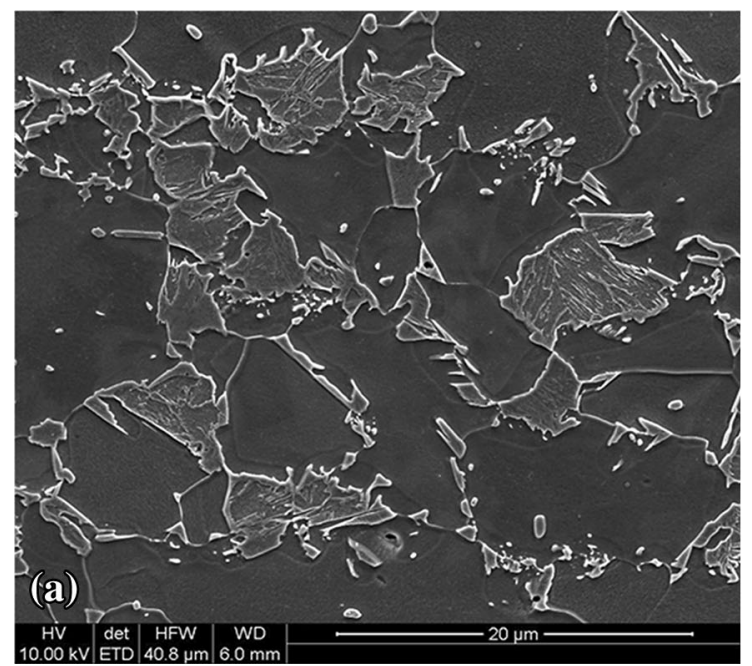

Selected microstructures are presented in Fig. 3-8. The following observations were made:

- Cycle 1 (Fig. 3): Microstructure is composed of ferrite $(75 \%)$ with the grain size of $5.8 \mu \mathrm{m}$ and hard constituents. The latter are in the form of grains containing bainite and martensite of the average size of $5.3 \mu \mathrm{m}$.

- Cycle 2 (Fig. 4): As in cycle 1, the microstructure is composed of ferrite $(72 \%)$ and hard constituents in the form of complex grains containing bainite and martensite. Volume fraction of bainite is larger than in cycle 1 . This is due to increase of austenite volume fraction and decrease of carbon content in this phase after long time at $810^{\circ} \mathrm{C}$.

- Cycle 3 (Fig. 5): The sample was heated to $810^{\circ} \mathrm{C}$, held for $10 \mathrm{~s}$ and then quenched right after this temperature was reached. The microstructure contained $75 \%$ of ferrite with the grain size of $4.0 \mu \mathrm{m}$ and hard constituents bainite and martensite. Volume fractions of these two phases were similar and the average size was $5.3 \mu \mathrm{m}$.

- Cycle 4 (Fig. 6): The sample was maintained at $810^{\circ} \mathrm{C}$ for $10 \mathrm{~s}$. The microstructure is similar to the sample after cycle 3 . Volume fraction of ferrite was $73 \%$ with the grain size of $5.3 \mu \mathrm{m}$.

- Cycle 5 (Fig. 7): After maintaining the sample at $810^{\circ} \mathrm{C}$ for $10 \mathrm{~s}$, it was subjected to two step cooling, slow and fast. During slow cooling austenite was transformed into ferrite and carbon content in austenite increased. In consequence martensite was the main hard constituent. Small amount of bainite was observed, as well. Volume fraction of ferrite was $74 \%$ with the grain size of $6.2 \mu \mathrm{m}$.

- Cycle 6 (Fig. 8): After maintaining at $810{ }^{\circ} \mathrm{C}$ for $10 \mathrm{~s}$ the sample was cooled to $450{ }^{\circ} \mathrm{C}$ and maintained at that temperature for $1200 \mathrm{~s}$. At the beginning of cooling about $50 \%$ of ferrite remained in the microstructure. The total volume fraction of ferrite after cooling was $80 \%$. The whole remaining austenite was transformed into bainite. Coagulation of the cementite particles followed.

Cycle 9 (Fig. 2) reflects typical industrial continuous annealing process. Cycles 7 and 8 (Fig. 2) were performed to investigate the microstructure after heating and after the end of the ferritic transformation, respectively. After the tests all

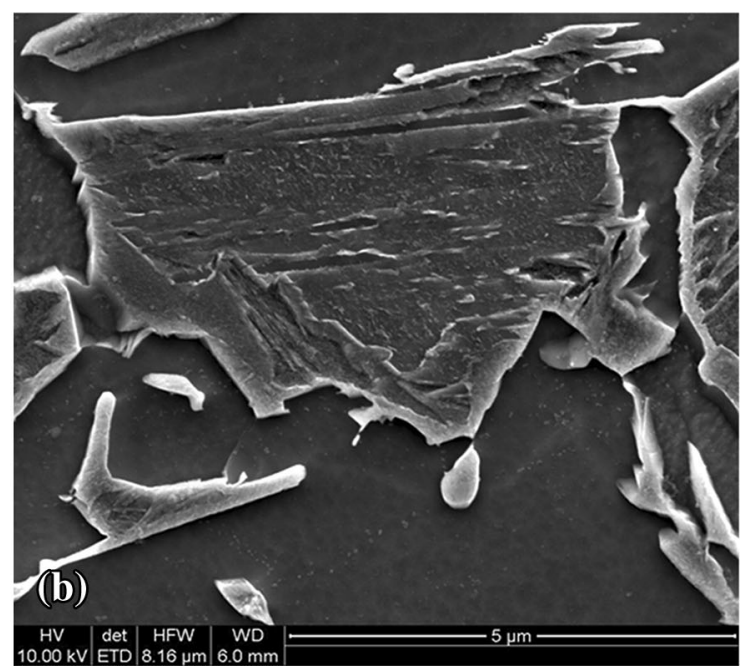

Fig. 3 Selected representative microstructures of the sample after thermal cycle 1 in Fig. 1 and Table 2 

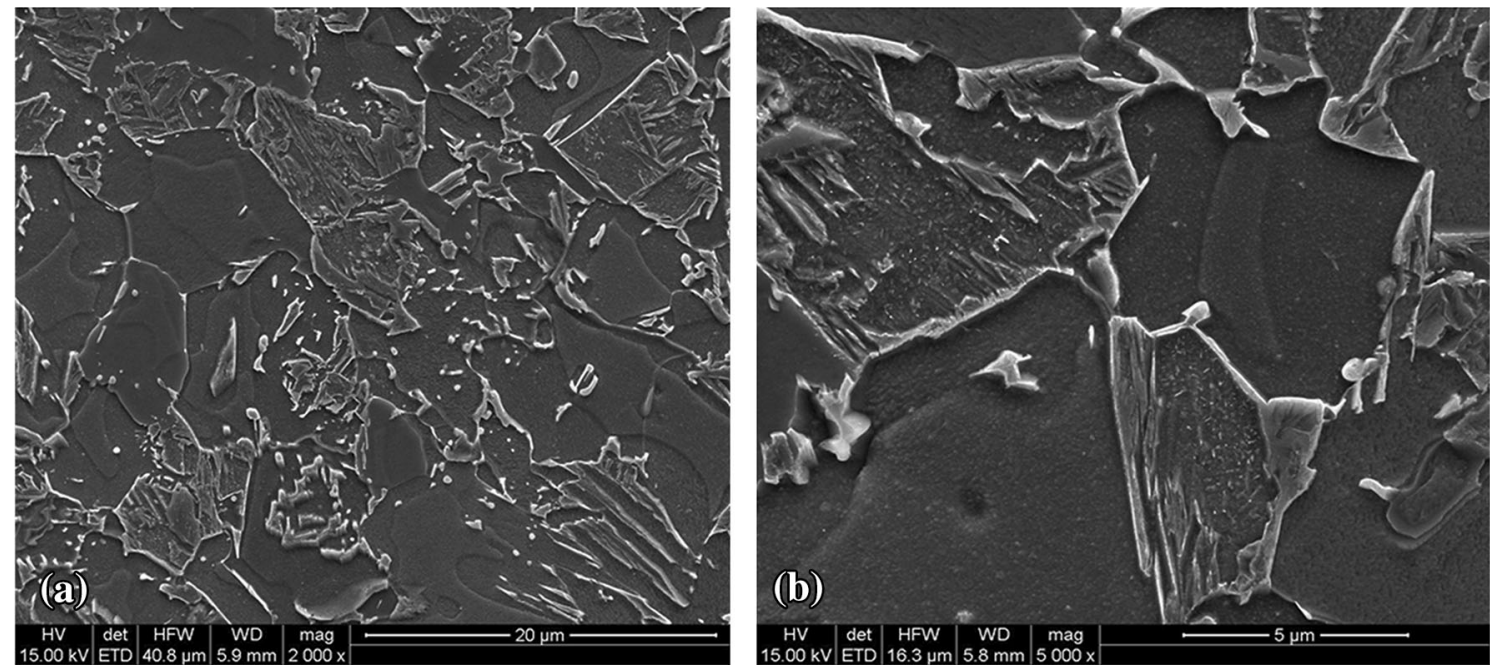

Fig. 4 Selected representative microstructures of the sample after thermal cycle 2 in Fig. 1 and Table 2
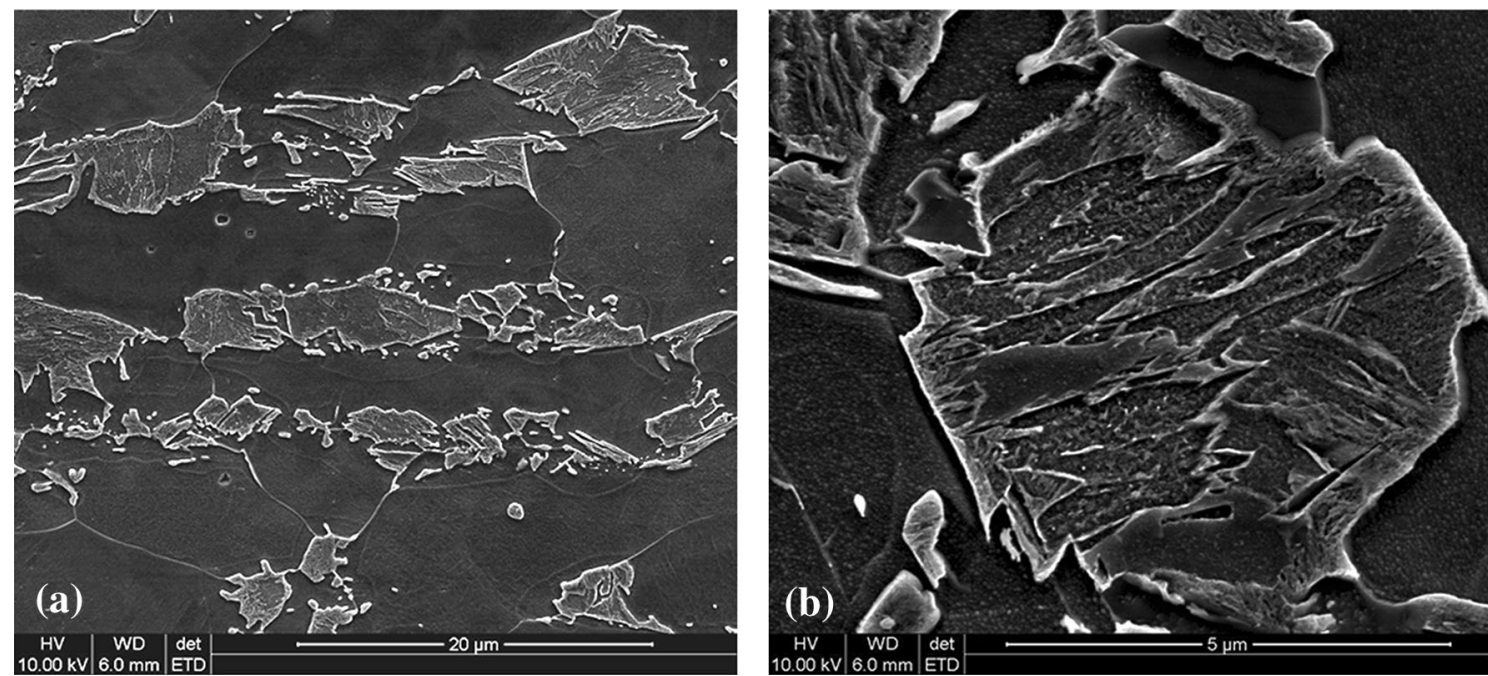

Fig. 5 Selected representative microstructures of the sample after thermal cycle 3 in Fig. 1 and Table 2
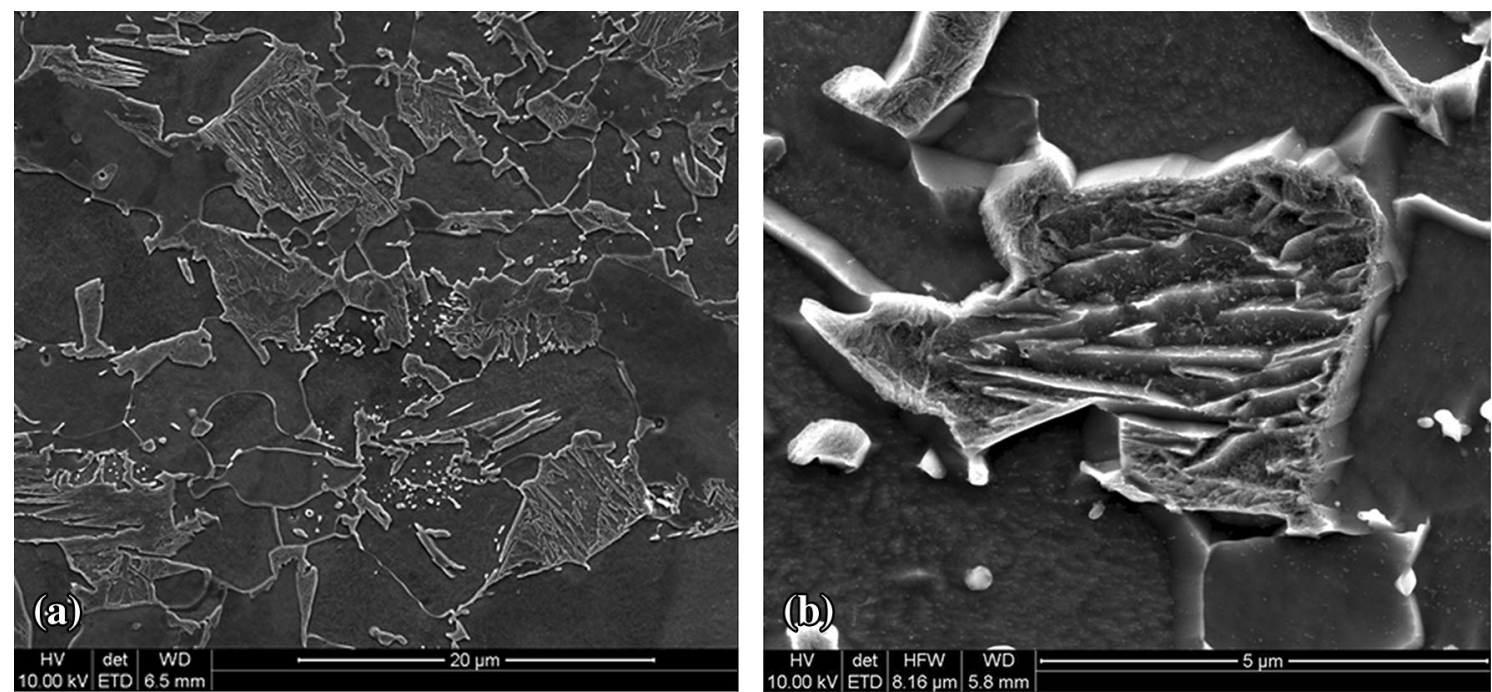

Fig. 6 Selected representative microstructures of the sample after thermal cycle 4 in Fig. 1 and Table 2 

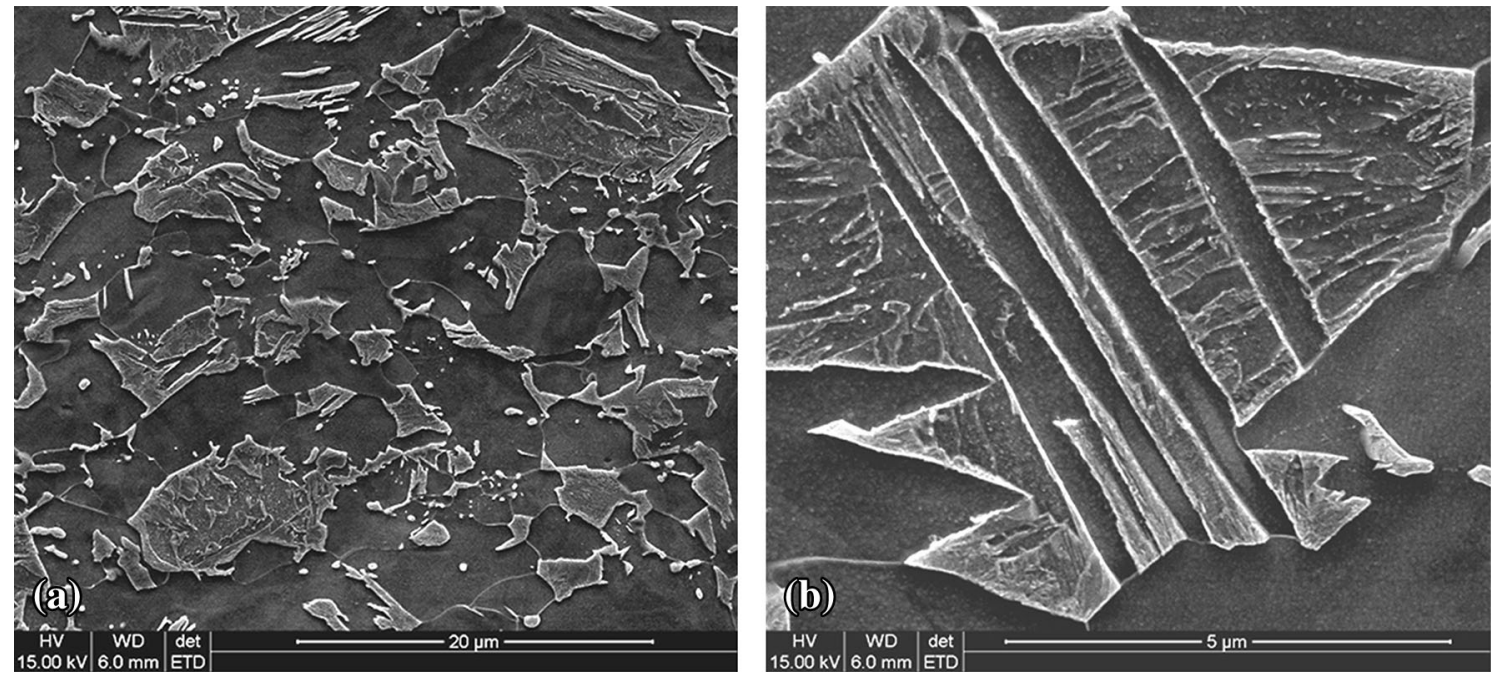

Fig. 7 Selected representative microstructures of the sample after thermal cycle 5 in Fig. 1 and Table 2
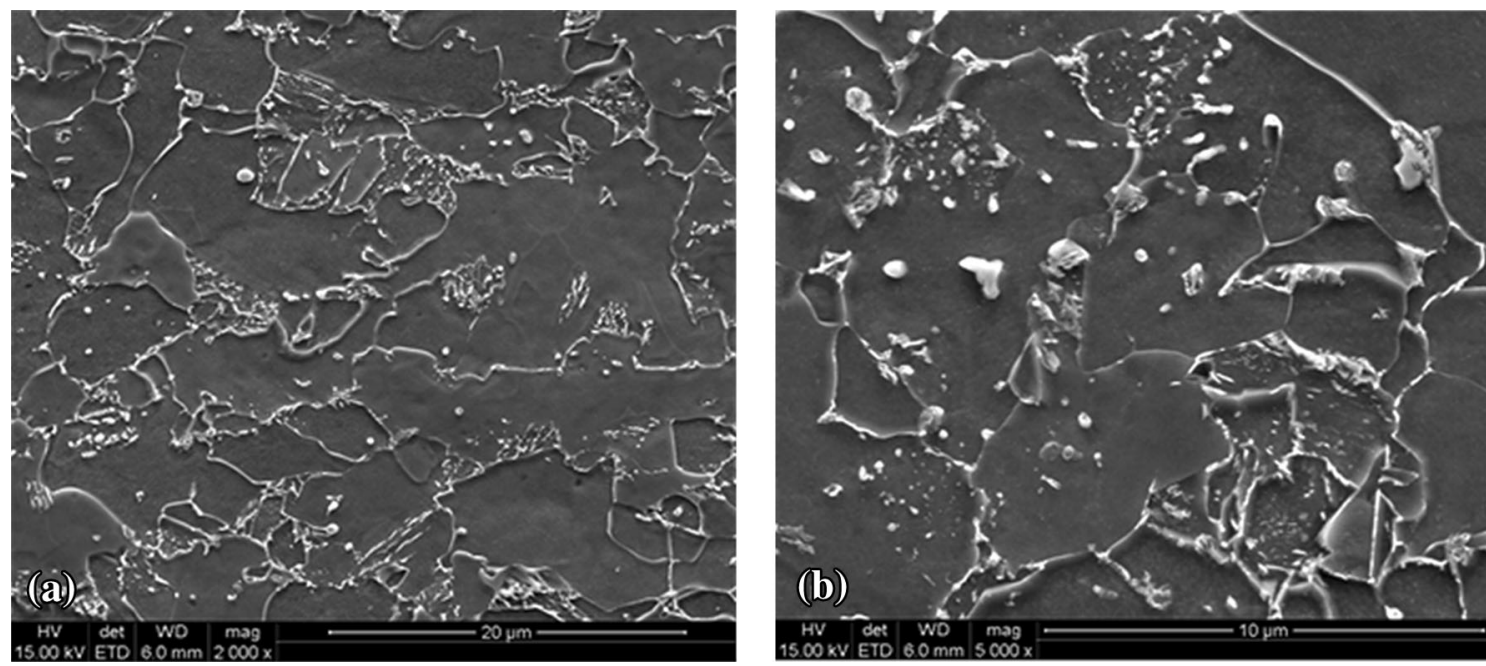

Fig. 8 Selected representative microstructures of the sample after the thermal cycle 6 in Fig. 1 and Table 2
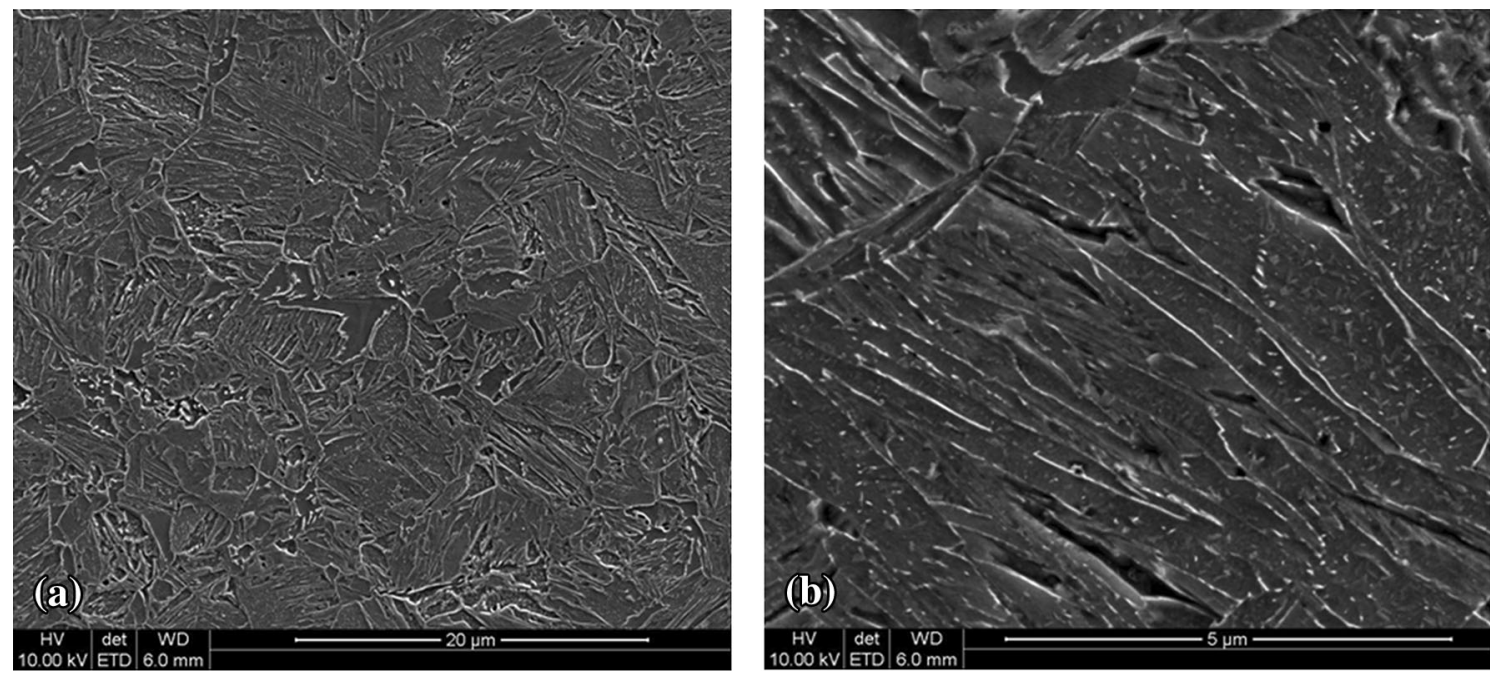

Fig. 9 Selected representative microstructures of the sample after the thermal cycle 7 in Fig. 2 

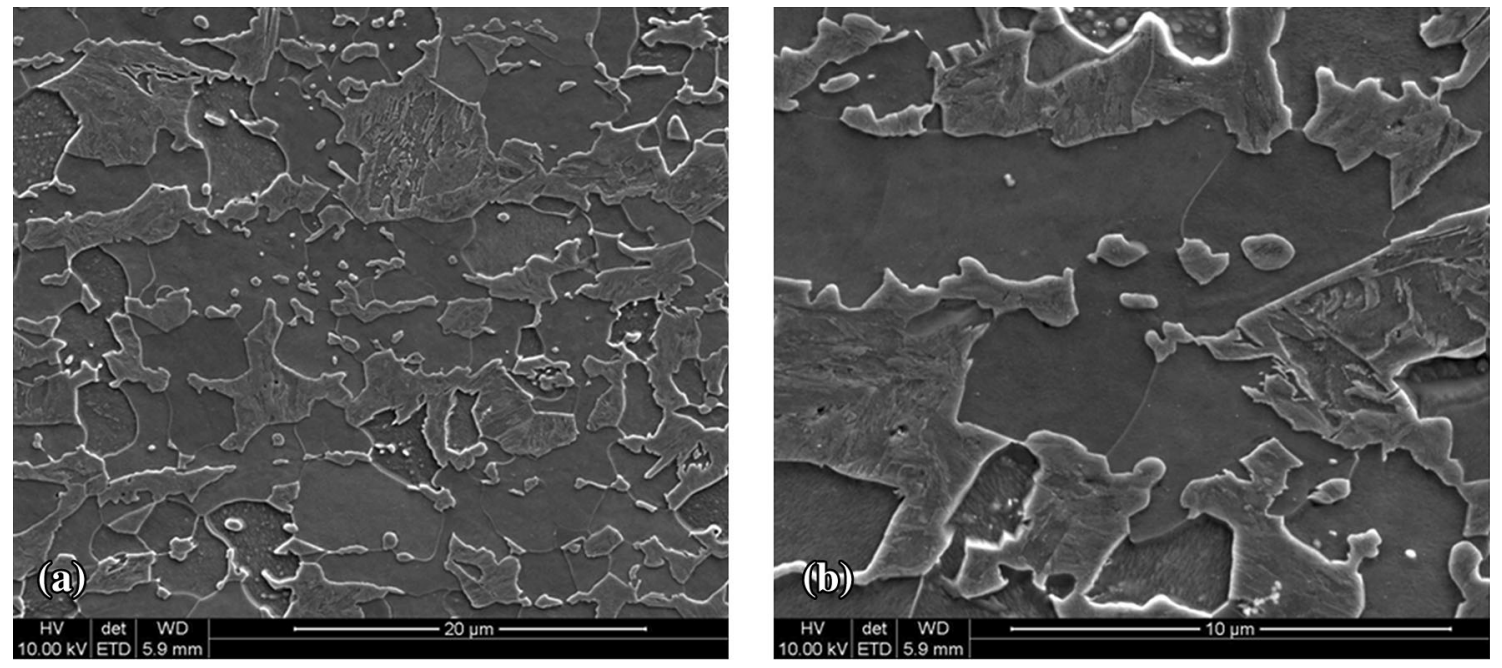

Fig. 10 Selected representative microstructures of the sample after the thermal cycle 8 in Fig. 2
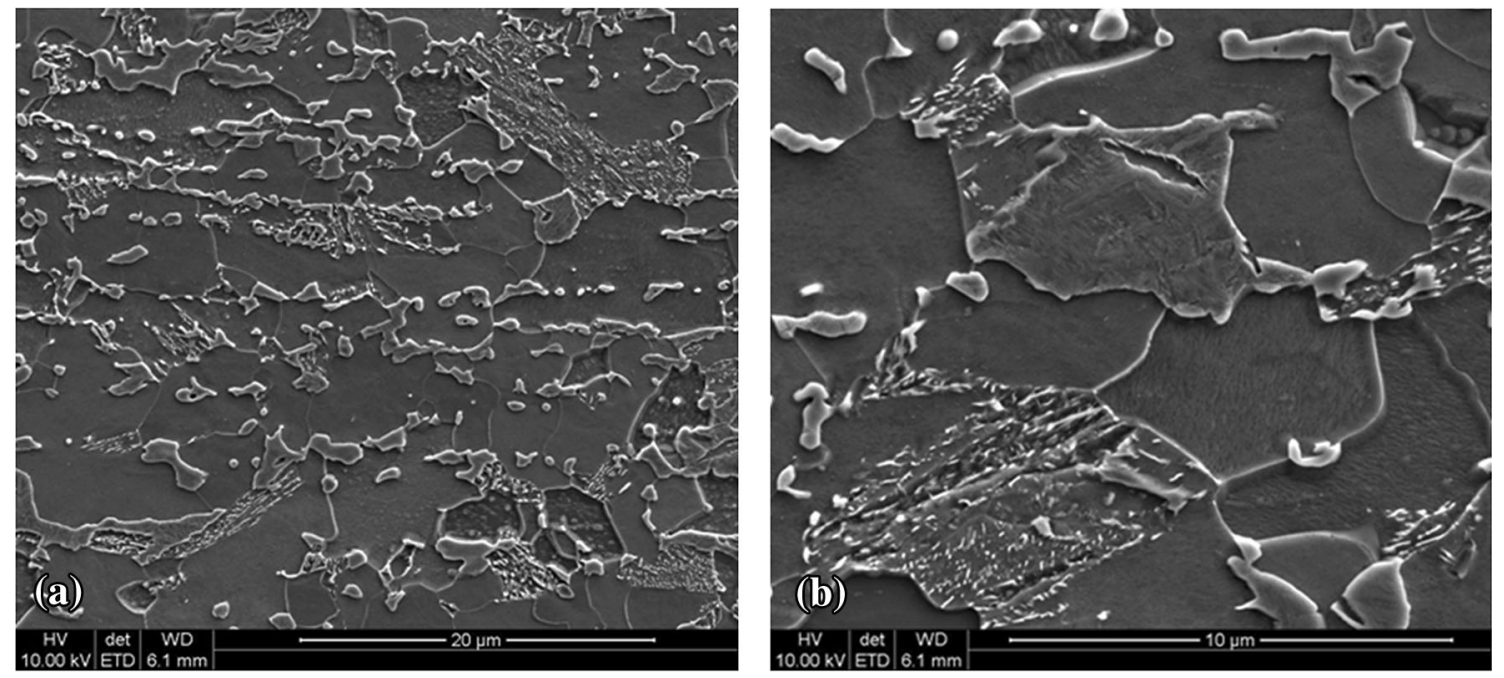

Fig. 11 Selected representative microstructures of the sample after the thermal cycle 9 in Fig. 2

Table 3 Equations in the model based on the upgrade of the JMAK equation

$\begin{array}{lr}X=1-\exp \left(-k t^{n}\right)(1) & k_{\mathrm{f}}=\frac{a_{5}}{D_{\gamma}} \exp \left[-\left(\frac{T-A_{\mathrm{e} 3}-\frac{400}{D_{\gamma}}+a_{6}}{a_{7}}\right)^{a_{8}}\right] \\ k_{\mathrm{b}}=a_{23} \exp \left(a_{22}-0.01 a_{21} T\right)^{-} & \tau_{\mathrm{b}}=\frac{a_{17}}{\left(B_{\mathrm{s}}-T\right)^{a_{19}}} \exp \left[\frac{a_{18}}{R(T+273)}\right] \\ \tau_{\mathrm{P}}=\frac{a_{9}}{\left(A_{\mathrm{e} 1}-T\right)^{a_{11}}} \exp \left[\frac{a_{10}}{R(T+273)}\right] & M_{\mathrm{s}}=a_{26}-a_{27} C_{\gamma} \\ B_{\mathrm{s}}=a_{20}-425[\mathrm{C}]-42.5[\mathrm{Mn}]-31.5[\mathrm{Ni}] & c_{\gamma \beta}=c_{\gamma \beta 0}+c_{\gamma \beta 1} T(3) \\ F_{\mathrm{m}}=\left(1-F_{\mathrm{f}}-F_{\mathrm{p}}-F_{\mathrm{b}}\right)\left\{1-\exp \left[-0.011\left(M_{\mathrm{s}}-T\right)\right]\right\} & \\ c_{\gamma \alpha}=c_{\gamma \alpha 0}+c_{\gamma \alpha 1} T(2) & \end{array}$

samples were subjected to microstructure analysis using scanning microscope. Selected microstructures are presented in Fig. 9-11.

Figure 9 shows microstructures after cycle 7. Bainite is a dominant component in this microstructure. Since the maximum temperature in the cycle was $856^{\circ} \mathrm{C}$, which is above $A_{c 3}$, the isolated ferrite grains (Fig. 9a) observed in the microstructure probably occurred during cooling. The mixture of upper and
Table 4 Equations in the model based on the CONT model

\begin{tabular}{lc}
\hline$B_{1}^{2} \frac{d^{2} X}{d t^{2}}+B_{2} \frac{d X}{d t}+X=f(T)(4)$ & $B_{1}=a_{4} \exp \left[-a_{5}\left(A_{e 3}-T\right)\right]$ \\
& $B_{2}=\left\{a_{6} \exp \left[-\left(\frac{a_{7}-T}{a_{8}}\right)^{2}\right]\right\}^{-1}$ \\
$f(T)=\frac{F_{f}}{F_{f \max }}$ & $F_{f \max }=1-\frac{\left(c-c_{\alpha}\right)}{\left(c_{\mathrm{eut}}-c_{\alpha}\right)}$ \\
\hline
\end{tabular}


Table 5 Coefficients in the model based on the upgrade of the JMAK equation

\begin{tabular}{|c|c|c|c|c|c|c|c|c|c|}
\hline$a_{4}$ & $a_{5}$ & $a_{6}$ & $a_{7}$ & $a_{8}$ & $a_{9}$ & $a_{10}$ & $a_{11}$ & $a_{12}$ & $a_{16}$ \\
\hline 1.479 & 7.104 & 145.9 & 36.77 & 2.092 & 1397 & 67.73 & 3.475 & 0.079 & 1.856 \\
\hline 1.62 & 8.405 & 171 & 72.59 & 2.68 & 21.0 & 0.371 & 0 . & 0.276 & 0.834 \\
\hline$a_{17}$ & $a_{18}$ & $a_{19}$ & $a_{20}$ & $a_{21}$ & $a_{22}$ & $a_{23}$ & $a_{24}$ & $a_{26}$ & $a_{27}$ \\
\hline 24.17 & 24.89 & 1.698 & 683.3 & 0.006 & 0.187 & 0.518 & 0.462 & 428 & 2.9 \\
\hline 29.03 & 26.34 & 1.682 & 722.7 & 3.569 & 2.95 & 4.066 & 3.5 & 409.1 & 21.44 \\
\hline
\end{tabular}

Table 6 Coefficients in the CONT model based on the upgrade of the Leblond equation

\begin{tabular}{llllc}
\hline $\boldsymbol{a}_{\mathbf{4}}$ & \multicolumn{1}{c}{$\boldsymbol{a}_{\mathbf{5}}$} & $\boldsymbol{a}_{\mathbf{6}}$ & $\boldsymbol{a}_{\mathbf{7}}$ & $\boldsymbol{a}_{\mathbf{8}}$ \\
\hline 32.98 & 0.0774 & 0.896 & 544.85 & 123.2 \\
19.92 & 0.086 & 0.807 & 664.86 & 78.81 \\
\hline
\end{tabular}

Table 7 Coefficients in Eq 2 and 3 in Table 3

\begin{tabular}{cccc}
\hline $\boldsymbol{c}_{\boldsymbol{\gamma} \boldsymbol{\mathbf { 0 }}}$ & $\boldsymbol{c}_{\boldsymbol{\gamma} \boldsymbol{\mathbf { 1 }}}$ & $\boldsymbol{c}_{\boldsymbol{\gamma} \boldsymbol{\beta 0}}$ & $\boldsymbol{c}_{\boldsymbol{\gamma} \boldsymbol{\beta} \mathbf{1}}$ \\
\hline 4.659 & -0.00554 & -1.1323 & 0.002443 \\
19.92 & 0.086 & 0.807 & 664.86 \\
\hline
\end{tabular}

lower bainite (Fig. 9b) is observed. Figure 10 shows microstructures after cycle 8 . Only martensite islands are seen in the ferritic matrix. Figure 11 shows microstructures after cycle 9. Martensite and bainite islands are observed in the ferritic matrix. Ferrite volume fraction is close to that observed in cycle 8 .

\section{Models}

\subsection{Basic Equations}

Phase transformation models were classified in Ref 19. Two models investigated in Ref 19 were considered in the present

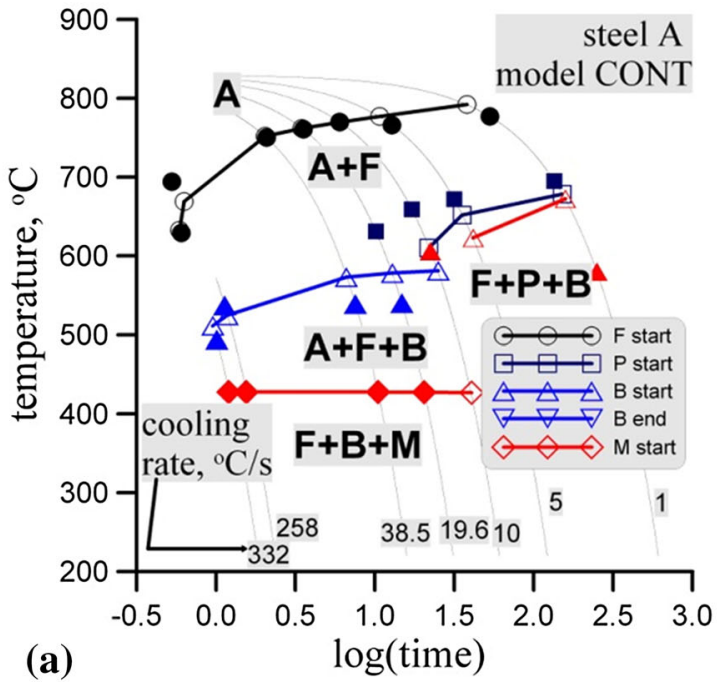

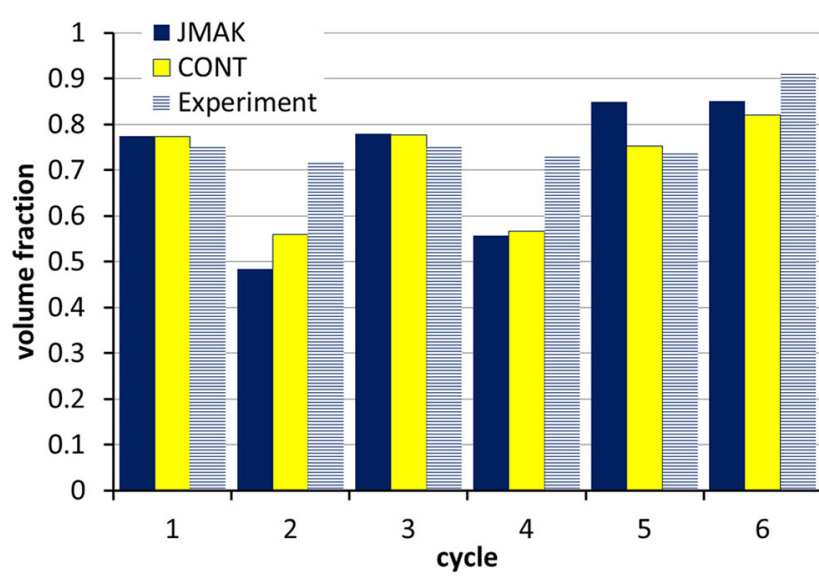

Fig. 13 Volume fractions of ferrite calculated by the two models and measured in experiments

work. The first was upgrade of the JMAK model which is described in detail in Ref 20. All equations of this model are given in Table 3. Notation in this table is as follows: $X$-volume fraction of a new phase, $t$-time, $D_{\gamma}$-austenite grain size, $k_{\mathrm{f}}, k_{\mathrm{p}}, k_{\mathrm{b}}$-coefficient $k$ in Eq 1 for ferritic, pearlitic and bainitic transformations, respectively $\left(k_{\mathrm{p}}=a_{15}\right.$ in the model), $\tau_{\mathrm{p}}, \tau_{\mathrm{b}}$-incubation time for pearlitic and bainitic transformations, $T$-temperature in $\mathrm{C}, R$-gas constant, $B_{\mathrm{s}}$, $M_{\mathrm{s}}$ - transformation start temperature in ${ }^{\circ} \mathrm{C}$ for bainitic and martensitic transformations, respectively, $C_{\gamma}$-average carbon

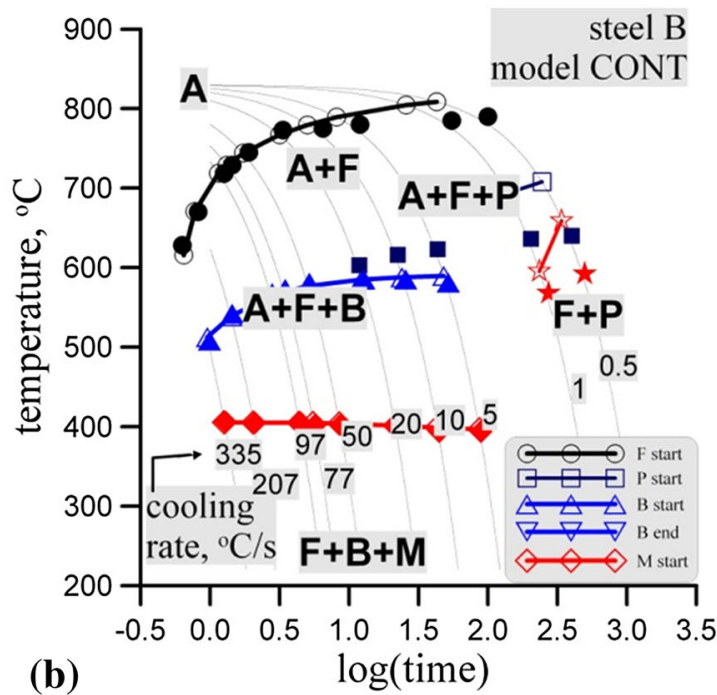

Fig. 12 Start and end transformations temperatures measured in the dilatometric tests (filled symbols) and calculated by the CONT model with the optimal coefficients in Tables 5 and 6 (open symbols) 

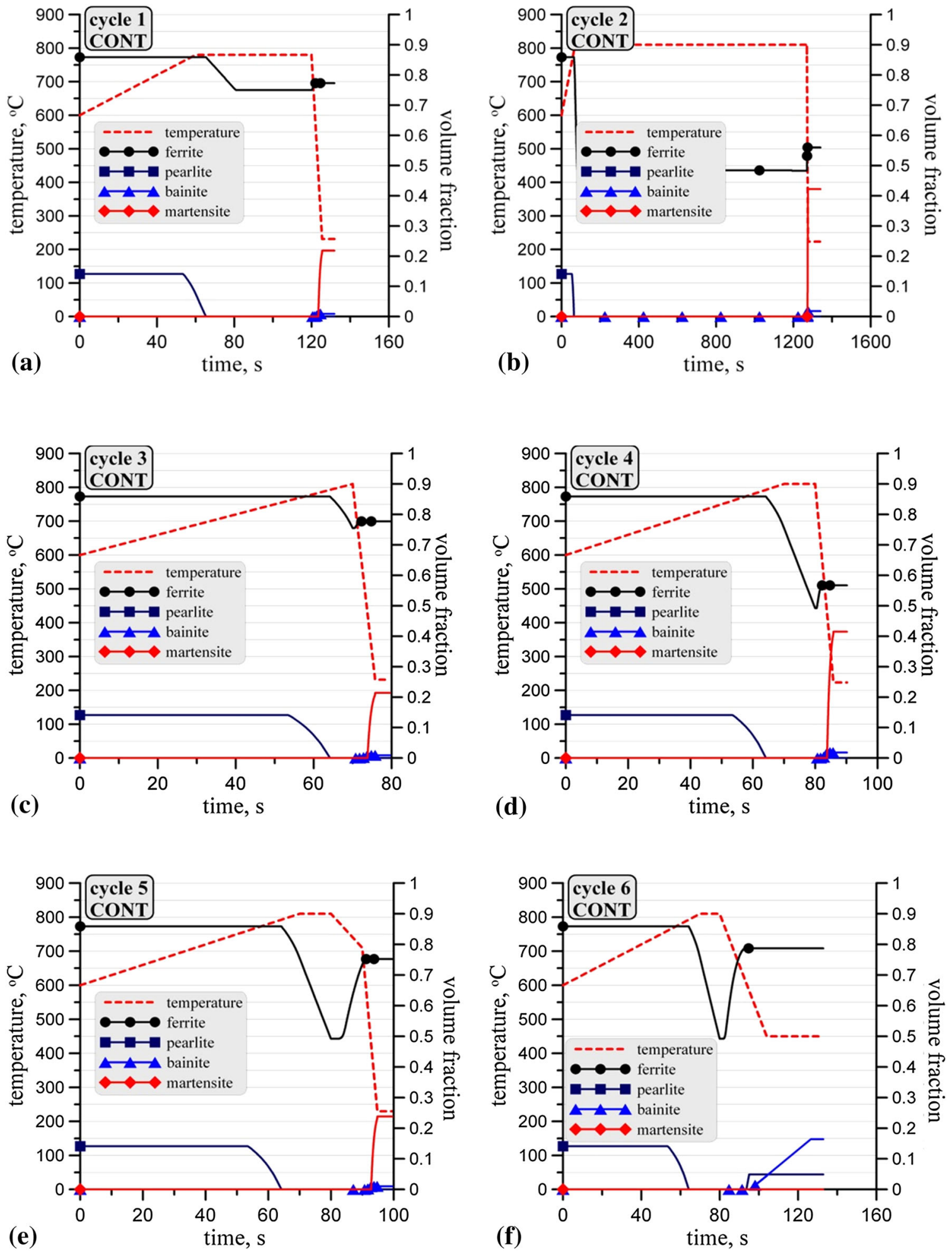

Fig. 14 Kinetics of transformations for laboratory tests 1-6 for steel A

content in the austenite, $F_{\mathrm{f}}, F_{\mathrm{p}}, F_{\mathrm{b}}, F_{\mathrm{m}}$,- - volume fractions of ferrite, pearlite, bainite and martensite, respectively, calculated with respect to the whole volume of the material, $c_{\gamma \alpha}$, $c_{\gamma \beta}$ _carbon content at the $\gamma-\alpha$ boundary and at the $\gamma$-cementite boundary, respectively. The values of $n$ in Eq 1 are represented in the model by coefficients $a_{4}, a_{16}$, and $a_{24}$ for ferritic, pearlitic, and bainitic transformations, respectively.

The second model is an upgrade of the Leblond model (Ref 14). The second order differential equation, which describes kinetics of the transformation, was introduced. Since the 

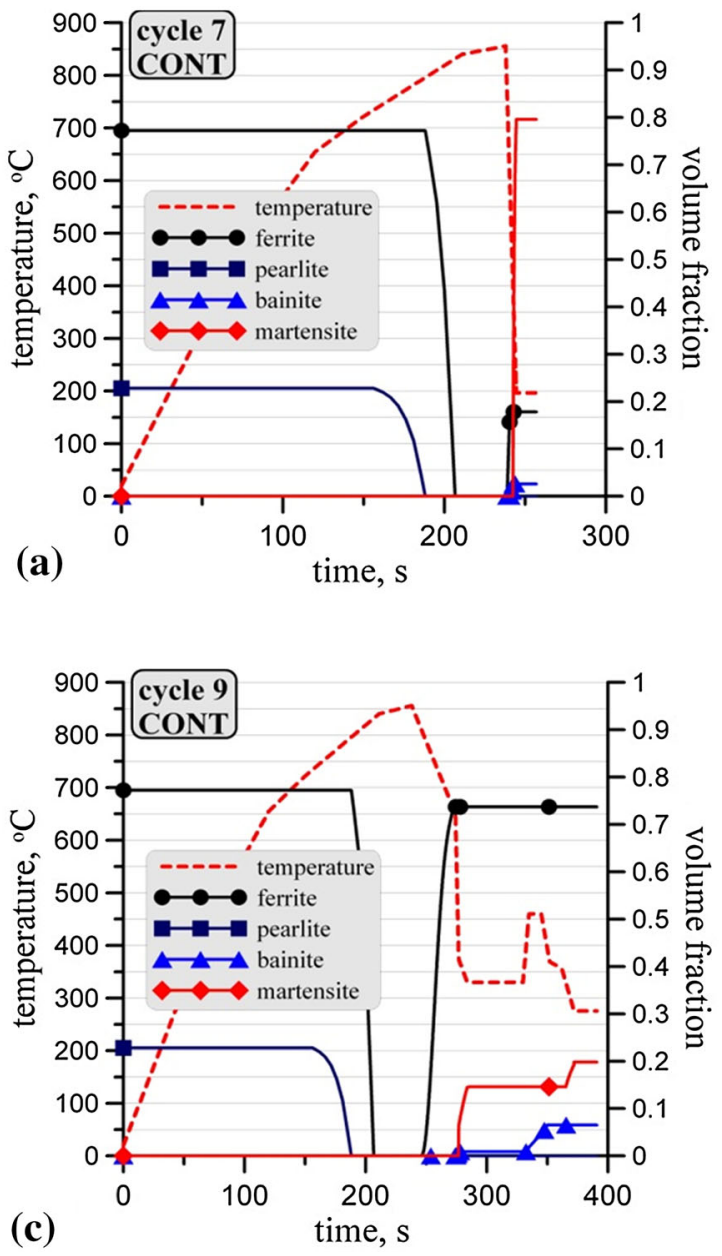

Fig. 15 Kinetics of transformations for laboratory tests 7-9 for steel B

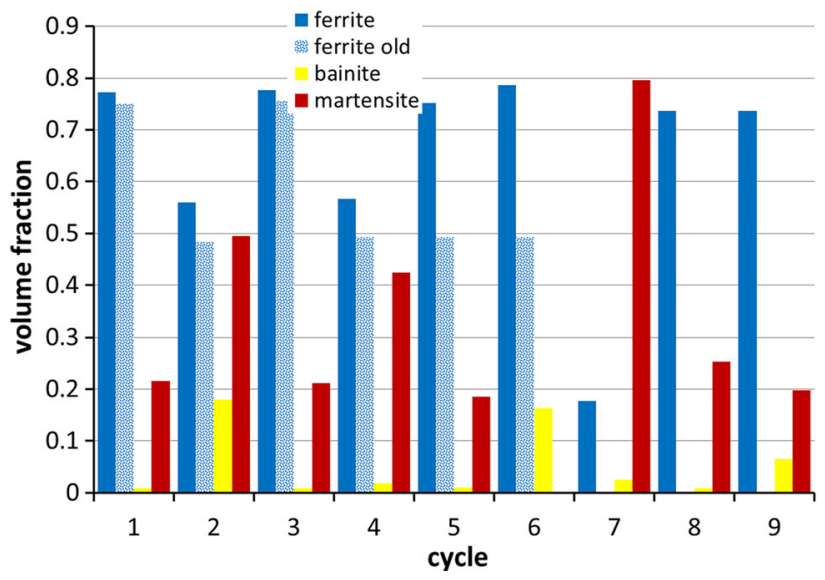

Fig. 16 Volume fractions of phases for all investigated thermal cycles (Color figure online)

mathematical formulation of this model is based on the control theory, it will be further referred to as CONT model. Details of this model are given in (Ref 17). This model was applied to the ferritic transformation only while the remaining transformations

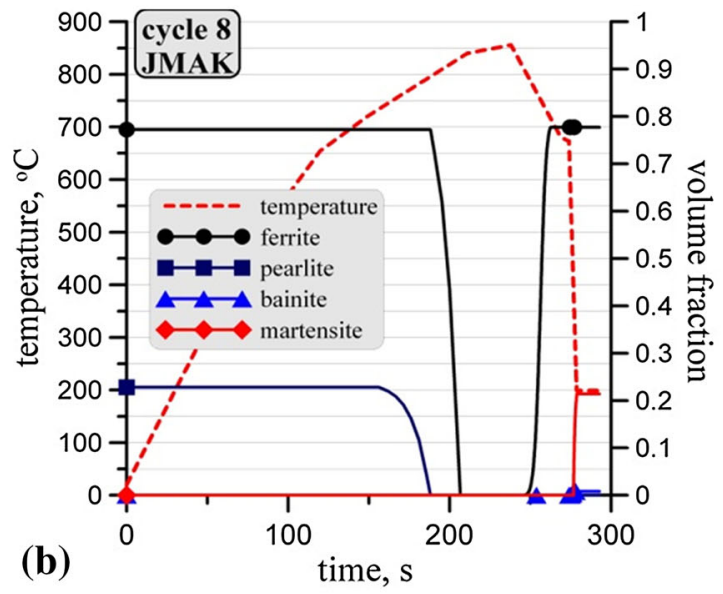

were described by the JMAK model in Table 3. Main equations of the upgrade of the Leblond model are given in Table 4. Notation in this table is as follows: $F_{\text {fmax }}$-maximum volume fraction of ferrite in a current temperature, $c$ - carbon content in steel, $c_{\alpha}$ - carbon content in ferrite, $c_{\text {eut }}$ - carbon content in eutectic temperature.

\subsection{Identification}

Upgrades of the JMAK and Leblond models contain a number of coefficients which are grouped in the vector $\mathbf{a}$. Values of these coefficients were determine for the investigated steels on the dilatometric tests performed with various cooling rates. Inverse algorithm described in Ref 20 was used for the identification and the values of coefficients are given in Table 5 for the JMAK model and in Table 6 for the CONT model, respectively. Coefficients in Eq 2 and 3 in Table 3, which describe equilibrium carbon content at phase interfaces, were calculated using ThermoCalc software and they are given in Table 7. In all tables upper row is for steel $A$ and lower row is for steel B.

Models with optimal parameters were verified by comparison calculated start and end transformations temperatures with 

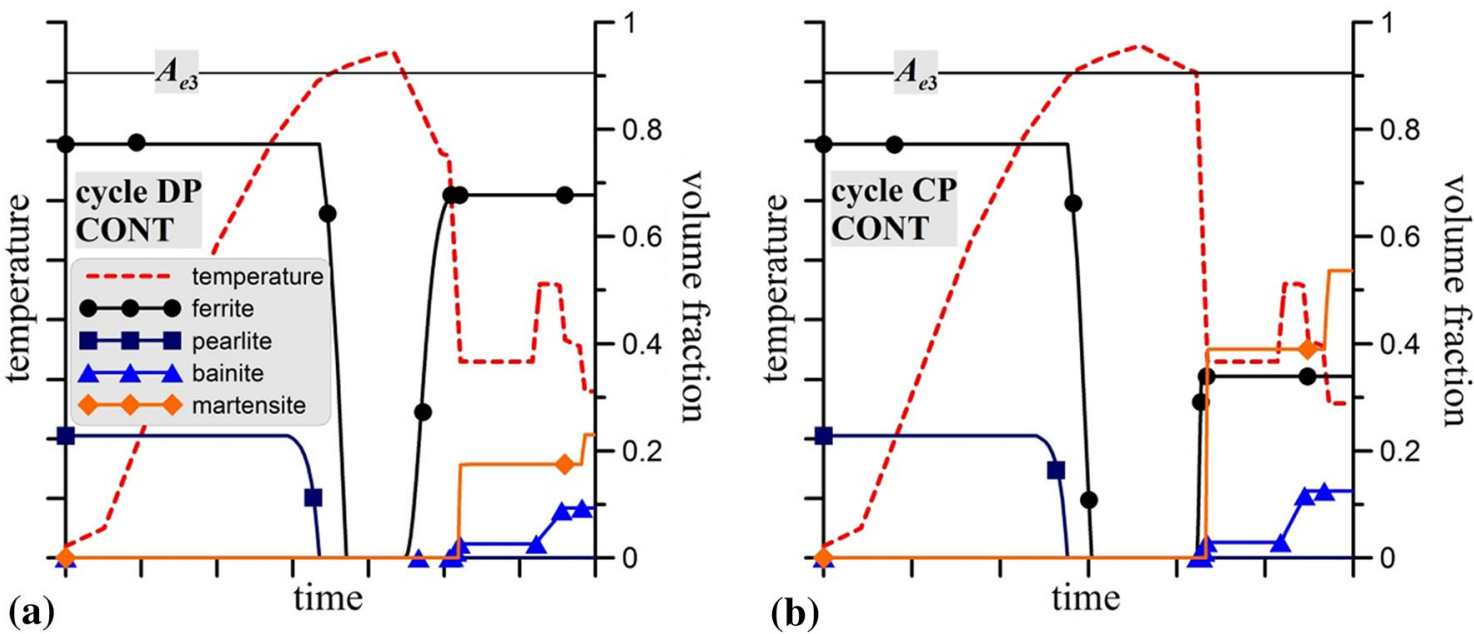

Fig. 17 Kinetics of transformations and time-temperature profiles (dashed lines) for the industrial continuous annealing thermal cycles: (a) DP cycle, (b) CP cycle

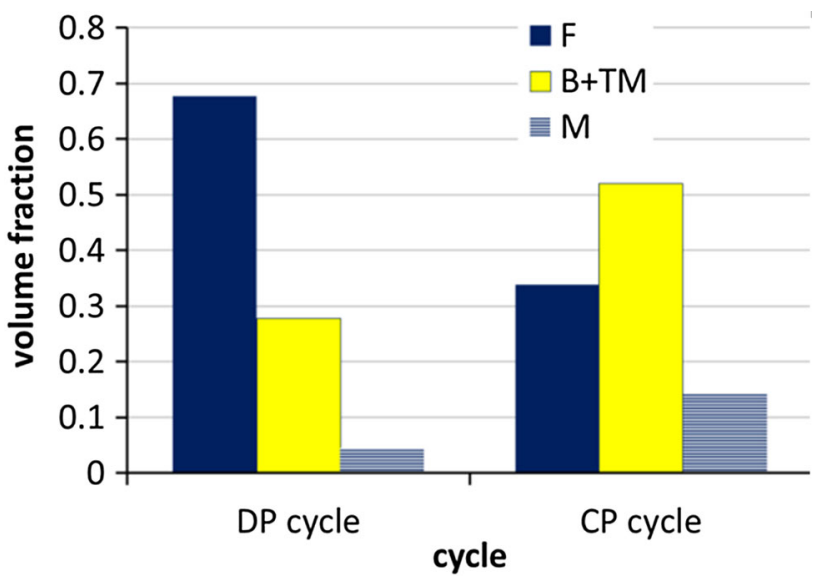

Fig. 18 Volume fractions of phases calculated using CONT model for the industrial annealing cycles presented in Ref 18 (TM stands for tempered martensite)

the measurements in the dilatometric tests. As far as JMAK is considered, this comparison is presented in Ref 21 for steel A and in Ref 18 for steel B. The results of the comparison for the CONT model are shown in Fig. 12. The two models described above were used for simulation of the thermal cycles presented in section 2 of this paper.

\section{Results}

\subsection{Kinetics of Transformation}

Calculated kinetics of transformations for all investigated laboratory tests are presented in Fig. 14 and 15. Timetemperature profile for each cycle is presented by the dashed line in each figure. Calculated volume fractions for all cycles are presented in Fig. 16. Calculated volume fractions of phases agree well with the experimental data (Fig. 13). Old ferrite is the ferrite, which was not transformed into austenite during heating.

\subsection{Industrial Annealing Cycles}

Validation of the models was performed by simulation of the industrial continuous annealing thermal cycles. Two cycles, one resulting in the DP and the second in the $\mathrm{CP}$ microstructure, were simulated. Details of these cycles and results of simulations using JMAK model are presented in Ref 18. Figure 17 shows kinetics of transformations and time-temperature profiles for the considered industrial thermal cycles and Fig. 18 shows volume fractions of structural components for these cycles calculated using CONT model. Martensite (M) in Fig. 18 represents only this part of martensite, which was not tempered during galvanizing process. These results correspond well to the values of $\mathrm{F}=60 \%, \mathrm{M}=10 \%$ and $\mathrm{B}+\mathrm{TM}=30 \%$ for the $\mathrm{DP}$ cycle and $\mathrm{F}=40 \%, \mathrm{M}=5 \%$ and $\mathrm{B}+\mathrm{TM}=55 \%$ for the $\mathrm{CP}$ cycle which were recorded in the microstructural observations in the industrial conditions (Ref 18).

\section{Conclusions}

Evaluation of application capability of simple phase transformation models in the simulation of thermal cycles characteristic for the continuous annealing was the objective of the paper. Two models were considered. The first was JMAK equation and the second was solution of the second order differential equation (CONT). Validation and verification of both models was performed. Experimental simulations of various thermal cycles were performed on the dilatometer DIL 805. The following conclusions were drawn:

- Dilatometric tests confirmed good accuracy of both models as far as prediction of volume fractions of phases in constant cooling rate conditions is considered. 
- Experimental simulations confirmed good accuracy of the models for more complex thermal cycles. Discrepancies between calculations and measurements were observed for the cycles where direct quenching from the intercritical region was applied.

- CONT model does not require additivity rule and is more suitable for simulations of complex thermal cycles.

- Capability of the CONT model to simulate the industrial continuous annealing line was confirmed.

\section{Acknowledgments}

Financial assistance of the NCN, Project No. 2011/03/B/ST8/ 06100, is acknowledged.

\section{Open Access}

This article is distributed under the terms of the Creative Commons Attribution 4.0 International License (http://creativecommons. org/licenses/by/4.0/), which permits unrestricted use, distribution, and reproduction in any medium, provided you give appropriate credit to the original author(s) and the source, provide a link to the Creative Commons license, and indicate if changes were made.

\section{References}

1. H. Hofmann, D. Mattissen, and T.W. Schaumann, Advanced Cold Rolled Steels for Automotive Applications, Steel Res. Int., 2009, 80, p 22-28

2. A. Grajcar, R. Kuziak, and W. Zalecki, Third Generation of AHSS with Increased Fraction of Retained Austenite for the Automotive Industry, Arch. Civ. Mech. Eng., 2012, 12(3), p 334-341

3. R. Kuziak, R. Kawalla, and S. Waengler, Advanced High Strength Steels for Automotive Industry, Arch. Civ. Mech. Eng., 2008, 8, p 103 117

4. C. Thomser, V. Uthaisangsuk, and W. Bleck, Influence of Martensite Distribution on the Mechanical Properties of Dual Phase Steels: Experiments and Simulation, Steel Res. Int., 2009, 80, p 582-587

5. M. Pietrzyk, J. Kusiak, R. Kuziak, Ł. Madej, D. Szeliga, and R. Gołąb, Conventional and Multiscale Modelling of Microstructure Evolution During Laminar Cooling of DP Steel Strips, Metall. Mater. Trans. B, 2014, 46, p 497-506

6. J. Rudnizki, B. Böttger, U. Prahl, and W. Bleck, Phase-Field Modeling of Austenite Formation from a Ferrite Plus Pearlite Microstructure
During Annealing of Cold-Rolled, Dual-Phase Steel, Metall. Mater. Trans. A, 2011, 42, p 2516-2525

7. M. Pietrzyk, R. Kuziak, K. Radwański, and D. Szeliga, Physical and Numerical Simulation of the Continuous Annealing of DP Steel Strips, Steel Res. Int., 2014, 85, p 99-111

8. C. Bos, M.G. Mecozzi, and J. Sietsma, A Microstructure Model for Recrystallisation and Phase Transformation During the Dual-Phase Steel Annealing Cycle, Comput. Mater. Sci., 2010, 48, p 692-699

9. C. Bos, M.G. Mecozzi, D.N. Hanlon, M.P. Aarnts, and J. Sietsma, Application of a Three-Dimensional Microstructure Evolution Model to Identify Key Process Settings for the Production of Dual-Phase Steels, Metall. Mater. Trans. A, 2011, 42, p 3602-3610

10. C. Halder, Ł. Madej, and M. Pietrzyk, Discrete Micro-scale Cellular Automata Model for Modelling Phase Transformation During Heating of Dual Phase Steels, Arch. Civ. Mech. Eng., 2014, 14, p 96-103

11. R. Gołąb, Ł. Madej, and M. Pietrzyk, The complex Computer System Based on Cellular Automata Method Designed to Support Modelling of Laminar Cooling Processes, J. Mach. Eng., 2014, 14, p 63-73

12. M. Pernach, K. Bzowski, and M. Pietrzyk, Numerical Modelling of Phase Transformation in DP Steel After Hot Rolling and Laminar Cooling, J. Multiscale Comput. Eng., 2014, 12, p 397-410

13. Ł. Rauch, R. Kuziak, and M. Pietrzyk, From High Accuracy to High Efficiency in Simulations of Processing of Dual-Phase Steels, Metall. Mater. Trans. B, 2014, 45, p 497-506

14. J.B. Leblond and J. Devaux, A New Kinetic Model for an Isothermal Metallurgical Transformations in Steel Including Effect of Austenite Grain Size, Acta Metall., 1984, 32, p 137-146

15. D. Homberg and W. Weiss, PID Control of Laser Surface Hardening of Steel, IEEE Trans. Control Syst. Technol., 2006, 10, p 896-904

16. P. Suwanpinij, U. Prahl, W. Bleck, and R. Kawalla, Numerical Cooling Strategy Design for Hot Rolled Dual Phase Steel, Arch. Civ. Mech. Eng., 2010, 81, p 22-28

17. I. Milenin, M. Pernach, and M. Pietrzyk, Application of the Control Theory for Modelling Austenite-Ferrite Phase Transformation in Steels, Comput. Methods Mater. Sci., 2015, 15, p 327-335

18. N. Kwiaton, R. Kuziak, and M. Pietrzyk, Comparison of Numerical Simulation and Experiment for the Microstructure Development of a Cold-Rolled Multiphase Steel During Annealing, Proc. Conf. MEFORM, R. Kawalla, Ed., Freiberg, 2016, Materials Science Forum 2016 (in press)

19. M. Pernach, K. Bzowski, I. Milenin, R. Kuziak, and M. Pietrzyk, New Trends in Efficient Modelling of Phase Transformations, Proc. Conf. METAL, Brno, 2015 on CD ROM

20. M. Pietrzyk and R. Kuziak, Modelling Phase Transformations in Steel, Microstructure Evolution in Metal Forming Processes, J. Lin, D. Balint, and M. Pietrzyk, Eds., Woodhead, Oxford, 2012, p 145-179

21. G. Górecki, R. Kuziak, N. Kwiaton, Ł. Madej, and M. Pietrzyk, DP_Builder-the Computer System for the Design of the Continuous Annealing Cycles for DP Steels. Computer Methods in Materials Science, 2015, 15 (in press) 